\section{Aphids (Insecta: Hemiptera: Aphididae) of Aligarh region of Uttar Pradesh, India}

\author{
M.K. Usmani ${ }^{1}$ \& Uzma Rafi ${ }^{2}$ \\ 1,2 Section of Entomology, Department of Zoology, Aligarh Muslim \\ University, Aligarh, Uttar Pradesh 202002, India \\ Email: ${ }^{1}$ usmanikamil94@gmail.com
}

Aphids are small, soft bodied insects belonging to the Family Aphididae of Order Hemiptera, and Suborder Homoptera. Around 4702 species of aphids are known world wide and 653 species are known from India (Rajendran 2002).

They are 'plant lice', sucking cell sap from their host plant and hence are serious agricultural pests. Aphids act as a vector of plant viruses and assume economic importance. About 300 species of aphids are vectors of 300 different viruses (Eastop \& Lambers 1976). In India nearly 1250 plant species belonging to 700 genera under 175 plant families are used as food plants by 653 species of aphids accommodated under 208 genera of aphids.

Important agricultural areas in different localities of Aligarh and I.A.R.I. Pusa, New Delhi were surveyed during 2006-2008 for aphid pests on agricultural crops. During the survey five species of aphids were recorded. This is the first systematic collection of aphids from Aligarh region.

In the present study, the authors followed Blackman \& Eastop (2000), Ghosh (1969), Ghosh \& Basu (1994), Kulkarni (2006), and Raychaudhuri (1980) in classifying aphids, on conventional morphological characters. Brief diagnosis of family, subfamily, tribe and genera with necessary keys of genera and species including colouration are given.

\section{Methods}

Aphids were collected from their host plants with a soft brush soaked in alcohol, fixed either in $96 \%$ alcohol or in fluid containing of two volumes of $96 \%$ alcohol and one volume of

Date of publication (online): 26 November 2009

Date of publication (print): 26 November 2009

ISSN 0974-7907 (online) | 0974-7893 (print)

Editor: Md. Equbal Ahmad

Manuscript details:

Ms \# 02164

Received 24 March 2009

Final received 13 November 2009

Finally accepted 20 November 2009

Citation: Usmani, M.K. \& U. Rafi (2009). Aphids (Insecta: Hemiptera: Aphididae) of Aligarh region of Uttar Pradesh, India. Journal of Threatened Taxa 1(11): 573577.

Copyright: @ M.K. Usmani \& Uzma Rafi 2009. Creative Commons Attribution 3.0 Unported License. JoTT allows unrestricted use of this article in any medium for non-profit purposes, reproduction and distribution by providing adequate credit to the authors and the source of publication.

Acknowledgments: We are thankful to Prof. Asif Ali Khan, Chairman, Department of Zoology, A.M.U. Aligarh for facilities. We are also thankful to Prof. Samiran Chakraborti, Deptartment of Zoology, University of Kalyani, Kalyani (W.B.) for help in identification. Financial support by the University Grant Commission to UR is acknowledged.

OPEN ACGESS | FREE DOWNLOAD

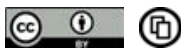

$75 \%$ of lactic acid and were mounted on slides, which were studied under light microscope. Measurements were done with ocular micrometer and camera lucida drawings were made. All measurements in $\mathrm{mm}$

\section{Taxonomic account}

Superfamily: Aphidoidea

Diagnostic Characters: Mouth parts present in both sexes. Antennae variable 1-6 segmented. They are polymorphic. Alatae forms with two pairs of transparent membranous wings, legs long and slender, tarsi 2 segmented, the basal segment sometimes reduced with paired claws, paired dorsal processes i.e. cornicles present on $5^{\text {th }}$ or $6^{\text {th }}$ abdominal segment.

\section{Family: Aphididae}

Diagnostic Characters: Radial sector is present in fore wing; Media of fore wing is branched. Cornicles nearly always present but vary in shape and size from very small pore like to very long and slender.

\section{Subfamily: Aphidinae}

Diagnostic Characters: Processus terminalis (p.t.) usually longer than base of last antennal segment, head and pronotum in apterae mutually free. Eyes always multifaceted, siphunculi and cauda usually elongate. Cauda longer than broad. Subanal plate never indented or bilobed. Empodial hairs always fine. Body sometimes with processi. Secondary rhinaria never subannular or ring like.

The subfamily Aphidinae is further divided into tribes.

\section{Tribe: Aphidini:}

Diagnostic Characters: Spiracles present on abdominal segments 1 and 2 placed far apart, lateral abdominal tubercles usually present on abdominal segment 1 and 7 , other segments with or without these tubercles; lateral frontal tubercles not or hardly developed; antennal hairs usually fine; antenna and body never densely pilose, apterae never with secondary rhinaria.

The tribe Aphidini is represented by two genera from this region. Key to genera of tribe Aphidini is given below.

Genus Aphis Linnaeus

Aphis Linnaeus, 1758, Nat.(10 ed), 1:451.

Type species: Aphis sambuci Linnaeus, 1758.

This genus is represented by three species from Aligarh and Delhi region.

\section{Aphis craccivora Koch}

(Fig. 1)

Aphis craccivora Koch, 1854, Die Pfl. Aphiden, 1:124.

Material examined: Four apterae on Dolichos Lablab purpureus (=Dolichos lablab) from Aligarh.

Distribution: Cosmopolitan, distributed through the tropical

Abbreviations: F.T.C. - First tarsal chaetotaxy; h.t.2 - Second tarsal segment of hind tibia; p.t. - Processus terminalis; u.r.s. - Ultimate rostral segment; I, II.....VI - Antennal segment I, II, III.....VI; Abdominal segment $1,2,3 \ldots \ldots 8$. 


\section{Key to Genera of Tribe Aphidini represented in these regions}

1. Abdominal dorsum of both apterae and alatae with spinules, those in apterae form distinct polygon encloses a few spinules; alatae with or without dorsal abdominal pigmentation ...... Rhopalosiphum Koch

2. Abdominal dorsum in apterae and alatae usually lacking spinules which if present, never forms polygons as above Aphis Linnaeus

\section{Key to the species of Aphis L.}

1. Secondary hairs on u.r.s. as long as to longer than primary hairs craccivora Koch Secondary hairs on u.r.s. shorter than primary hairs

2. Second tarsal segment with both dorsal and ventral secondary hairs; siphunculi stout brown to dark brown, $1.25-1.30$ x segment III nerii B. d. Fonscolombe Second Tarsal segment with secondary hairs only ventrally; siphunculi subequal to or just longer than segment III gossypii Glover

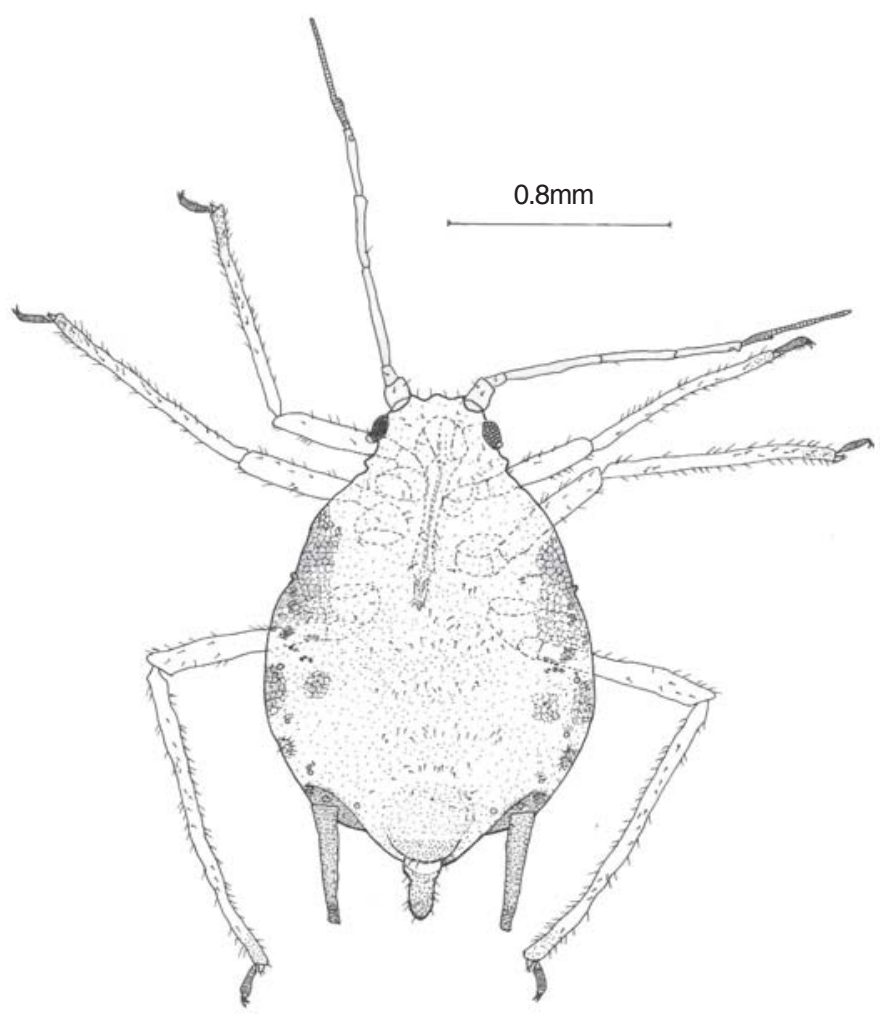

Figure 1. Aphis craccivora Koch (Apterous)

region.

Diagnostic characters: Small sized aphid, adults shiny black and nymphs light brown; siphunculi and cauda black. Abdomen dorsally black and completely sclerotic, pigmentation extending towards the lateral sides to enclose lateral sclerites and to encircle bases of siphunculi. Antenna slightly shorter to slightly longer than body. Antennal segments I, II, and apex of V dark, segments III, IV and base of V pale. Siphunculi longer than cauda and imbricated, Cauda with 4-7 hairs.

Aptera: Length of body 1.94, width 1.28; antennae 1.48, segments III: IV: V: VI 0.36: 0.27: 0.24: (0.13+0.30); u.r.s. 0.12; h.t.2 0.14; siphunculus 0.42; cauda 0.26 .

Alata: (From Lit.) Length of body 2.22, width 1.03; antennae 1.42, segments III: IV: V: VI 0.32: 0.28: 0.26:(0.12+0.32); u.r.s. 0.10; h.t.2 0.12; siphunculus 0.28; cauda 0.19.

Hosts: Plants belonging to the families Malvaceae, Fabaceae, Asteraceae, Amaranthaceae, Cucurbitaceae,
Convolvulaceae, Solanaceae etc.

Seasonal occurrence: Throughout the year. During JuneJuly and January-February, it makes enormous colonies on Gliricidia maculata.

Natural enemies: Cheilomenes sexmaculata recorded from Aligarh on Aphis craccivora. Yellowish orange colored beetle having two black transverse bands and a round spot on each elytra. Larvae and adults are voracious feeders.

\section{Aphis gossypii Glover}

(Figs. 2 \& 3)

Aphis gossypii Glover, 1877, Rep. comm. Agric. Oper. Dep., (1876), 36.

Material examined: Two alatoid nymphs, two alate and four apterous adults on Brassica compestris, Coriandrum satioum, from Aligarh and on Coccinia indica and Gossypium from I.A.R.I. New Delhi.

Distribution: Cosmopolitan.

Diagnostic characters: Small to medium in size. Apterae variable in color, large specimens usually greenish-black. Nymphs light green with dark siphunculi and a pale or dusky

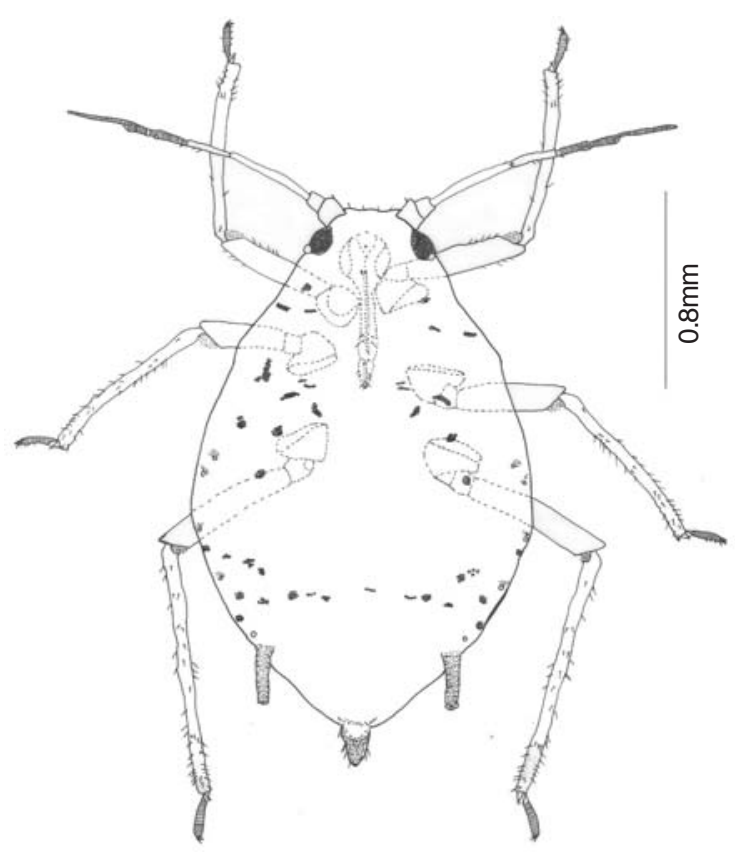

Figure 2. Aphis gossypii Glover (Apterous) 


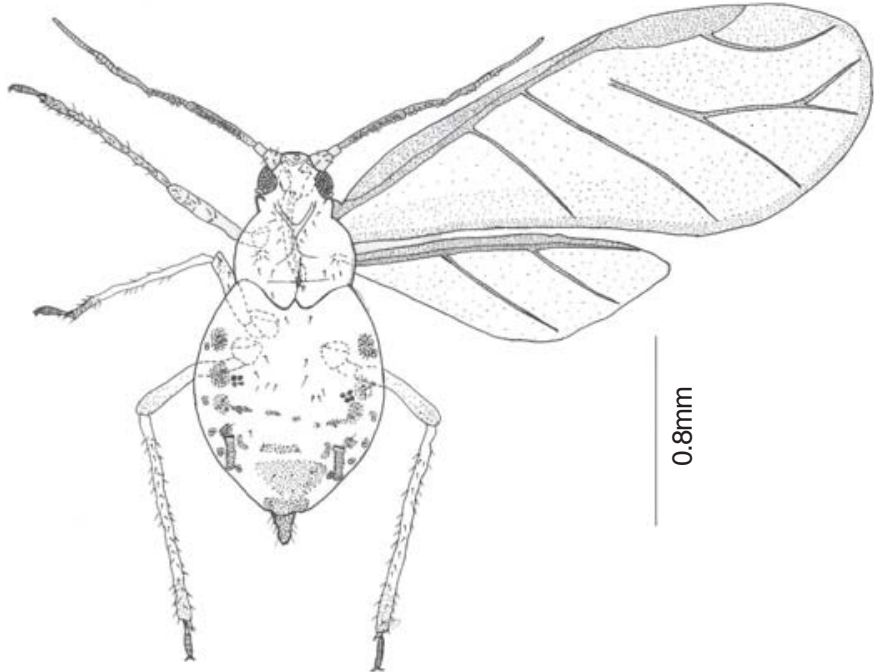

Figure 3. Aphis gossypii Glover (Alata)

cauda. Antenna six segmented, secondry rhinaria absent in apterae while found in alatae on antennal segment III, IV, and V. Segments I, II, apical side of processus terminalis and area around the primary rhinarium of segment VI dark; remaining part of antennae pale. Cauda broadly rounded on apical side, often with 4-7 hairs and dusky but lighter than siphunculi. Abdominal dorsum without any pigmentation.

\section{Population I: (Brassica compestris)}

Aptera: length of body 2.3, width 1.41; antenna 1.22 segments III:IV:V:VI 0.37:0.18:0.15:(0.11+0.26); u.r.s. 0.11; h.t.2 0.14; siphunculus 0.23 , cauda 0.2 .

Population II: (Coccinia indica).

Aptera: length of body 1.65, width 1.09; antenna 1.66, segments III:IV:V:VI 0.35:0.25:0.23:(0.10+0.56); u.r.s. 0.10; h.t.2 0.11; siphunculus 0.25 , cauda 0.17 .

Population III: (Gossypium sp.)

Aptera: length of body 1.65, width 0.95; antenna 1.03, segments III:IV:V:VI 0.26:0.18:0.16:(0.10+0.22); u.r.s. 0.10; h.t.2 0.10; siphunculus 0.34 , cauda 0.17 .

Alata: Length of the body 1.57, width 0.73 ; antenna 1.21, segments III:IV:V:VI 0.30:0.21:0.18:(0.13+0.26); u.r.s. 0.11; h.t.2 0.10; siphunculus 0.22; cauda 0.12.

Hosts: Brassica compestris, Coriandrum sativum, Coccinia indica, Gossypium sp. and plants belonging to the families Solanaceae, Cruciferae, Cucurbitaceae etc.

Seasonal occurrence: Throughout the year

Natural enemies: Coccinella transversalis Fabricius found on Aphis gossypii, an orange-red colored beetle having three transverse bands on elytra. Adults and larvae feed on aphids. Uniformly distributed throughout the country.

\section{Aphis nerii Boyer de Fonscolombe}

(Fig. 4)

Aphis nerii Boyer de Fonscolombe, 1841, Ann. Soc. Ent. Fr., 10:179.

Material examined: Two Alatoid nymphs and three Apterous on Calotropis sp. from Aligarh and on Platycodon sp. (Balloon flower) from I.A.R.I., Delhi.

Distribution: All over India; Africa, America, Europe, Japan, Java, Korea, Middle East and Taiwan.

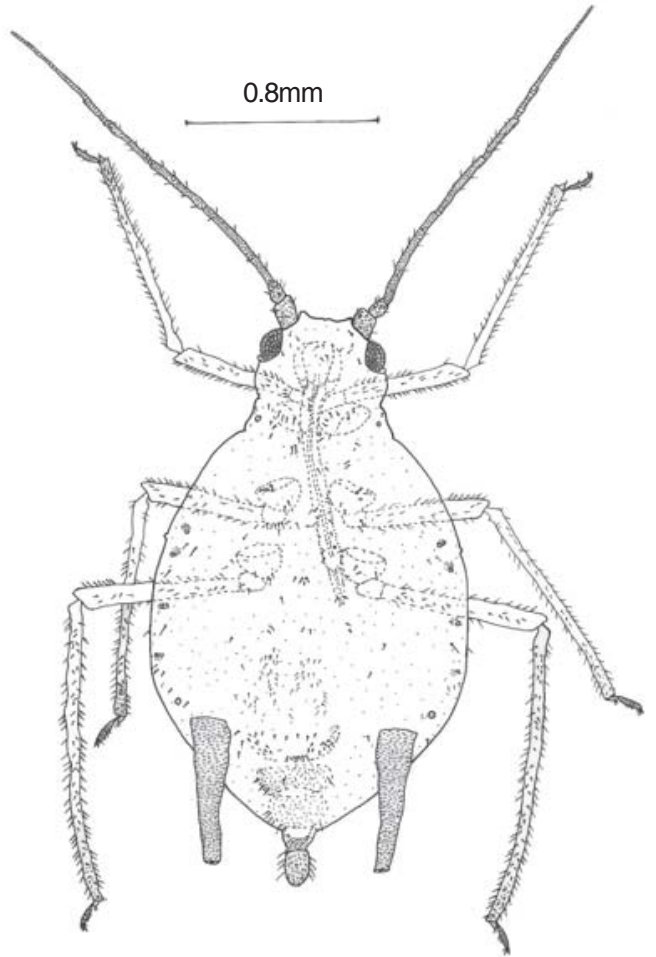

Figure 4. Aphis nerii Boyer de Fonscolombe (Apterous)

Diagnostic characters: Apterae of this species bright orangeyellow coloured with black siphunculi and cauda; antennae and legs predominantly dark. Alatae yellow in colour with dark wing veins and pigmented thorax. Antenna shorter than body, apical sides of segments I and III dusky, segment II and apical side of II and apical side of IV and V and whole VI dark. Siphunculi and cauda black; siphunculi longer than cauda, cauda with 9-18 hairs.

Aptera: length of body 2.34, width 1.4; antenna 1.71, segments III:IV:V:VI 0.46:0.30:0.25:(0.11+0.43); u.r.s. 0.18; h.t.2 0.11; siphunculus 0.6, cauda 0.28 .

Alata: (From Lit.) Length of the body 2.25, width 1.01; antenna 1.53, segments III:IV:V:VI 0.44:0.34:0.26:(0.13+0.48); u.r.s.0.14; h.t.2 0.12; siphunculus 0.43; cauda 0.20 .

Hosts: Calotropis sp., Platycodon sp. Asclepias curassavica, etc.

Seasonal occurrence: June-July and January-February

Natural enemies: Cheilomenes sexmaculata (F.), Coccinella transversalis F. (Coleoptera: Coccinellidae).

Note: This is the first record from Aligarh region.

\section{Genus Rhopalosiphum Koch}

Rhopalosiphum Koch, 1854, Die pft. Aphiden. 1:23. Type-species: Aphis nymphae Linnaeus, 1761.

\section{Rhopalosiphum padi (Linnaeus)}

(Fig. 5)

Aphis padi Linnaeus 1758, Syst. Nat. (10 ed), 1:451.

Material examined: Four alatoid nymphs on Cynodon sp. from Aligarh and I.A.R.I. and on Andropogon sp. from I.A.R.I. campus.

Distribution: Cosmopolitan.

Diagnostic characters: Body is oval, yellowish-green or olive green to greenish-black; often with rust-coloured patches around 
Key to species of Rhopalosiphum Koch.

1. Antennae 5 segmented, p.t. about $5.3-6.2 \mathrm{x}$ base of last antennal segment; body about $7.70-11.20 \mathrm{x}$ siphunculi; abdominal dorsum covered with long and fine hairs; siphunculi $1.7-1.8$ times longer than cauda

rufiabdominalis (Sasaki)

Antenna 6 segmented, p.t. about $4.06-5.33$ x base of last antennal segment; body about $6.0-8.66$ x siphunculi; abdominal dorsum hairs with blunt apices; siphunculi more than 1.5 times as long as cauda padi (L.)

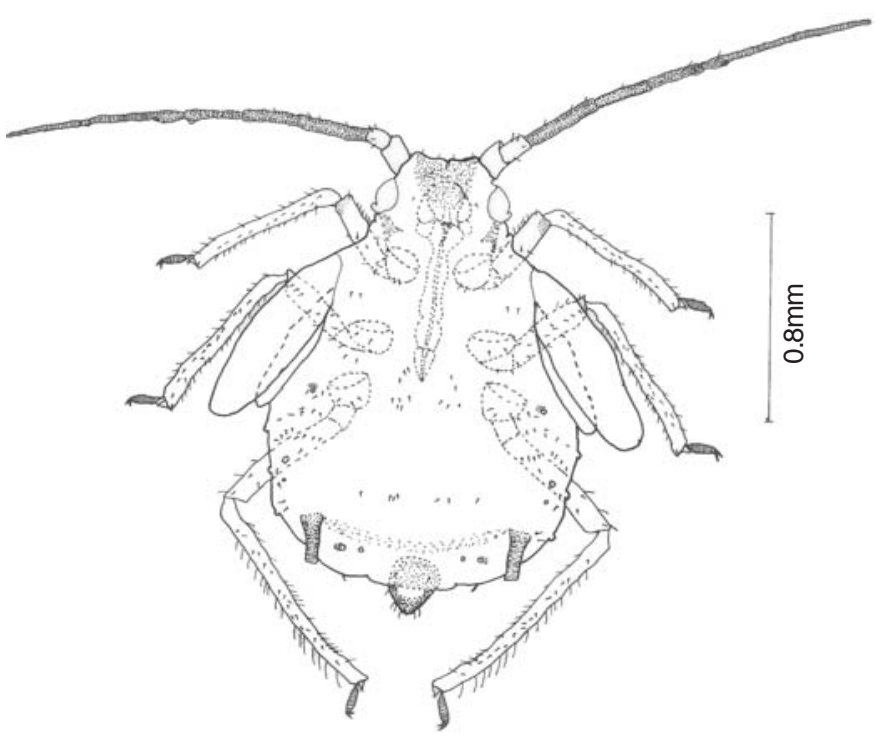

Figure 5. Rhopalosiphum padi (Linnaeus) (Alatoid nymph)

the bases of siphunculi and on dorsum of abdomen. Alatae have pale to dark green abdomen. Antennae shorter than body. Processus terminalis about three to four times longer than the base of last antennal segment. Secondry rhinaria absent in aptarae, while present in alatae forms, segment III with 16, IV with five and $\mathrm{V}$ with two secondary rhinaria; fine hairs present on flagellum in both cases. Siphunculi longer than cauda. Cauda uniformly dark, but in black specimens, paler at the base.

Aptera: length of body 2.10, width 1.30; antenna 1.45, segments III:IV:V:VI 0.32:0.17:0.22:(0.10+0.49); u.r.s. 1.12; h.t.2 0.11; siphunculus 0.07 , cauda 0.04 .

Alata: Length of the body 1.47, widh-0.84; antenna 1.18, segments III:IV:V:VI 0.30:0.14:0.14:(0.89+0.41); u.r.s.0.09; h.t.2 0.02; siphunculus 0.05; cauda 0.03 .

Hosts: Plants belonging to Acanthaceae, Canaceae, Cyperaceae, Poaceae, Oxalidaceae and Polygonaceae.

Seasonal occurrence: November-December.

Natural enemies: Coleoptera: Coccinellidae: Cheilomenes sexmaculata $(\mathrm{F}$.)

\section{Rhopalosiphum rufiabdominalis (Sasaki)} (Fig. 6)

Toxoptera rufiabdominalis Sasaki, 1899, Rep. Hokkaido natr. Agric. Exp. Stn, 17:202

Material examined: Four Apterous and 10 nymphs on Sorghum sp. from Aligarh and I.A.R.I.

Distribution: Cosmopolitan.

Diagnostic characters: Apterae light green to dark green with usually a reddish area at the posterior end of abdomen between and around siphunculi. Alatae also similarly colored.
Antennae very short almost half of the body length. Processus terminalis 4-5 times longer than the base of last antennal segment. Secondary rhinaria absent in aptera. Abdominal dorsum covered with fine hairs, well developed pattern of polygonal reticulation present on dorsum of apterae and each polygon encloses a group of spinules. Siphunculi longer than cauda. Cauda lighter than Siphunculi in younger specimens but dark in adults. Has only five-segmented antennae; but the specimens studied had six segmented antennae.

Aptera: Length of body 1.87 width 1.09; antenna 0.95 , Segments III:IV:V 0.30:0.14:(0.09+0.30); u.r.s 0.07; h.t.2 0.08; siphunculus 0.12; Cauda 0.15

Alata: (From Lit.) Length of the body 2.34, width 1.23; antenna 1.42, segments III:IV:V 0.50:0.17:(0.10+0.53); u.r.s 0.13 ; h.t.2 0.10; siphunculus 0.06; cauda 0.03..

Hosts: Plants belonging to Aroidae, Canaceae, Ericanaceae, Fagaceae, Poaceae, Liliaceae, Malvaceae, Fabaceae, Rosaceae and Solanaceae.

Seasonal occurrence: May-July, September-November. Natural enemies: Not found.

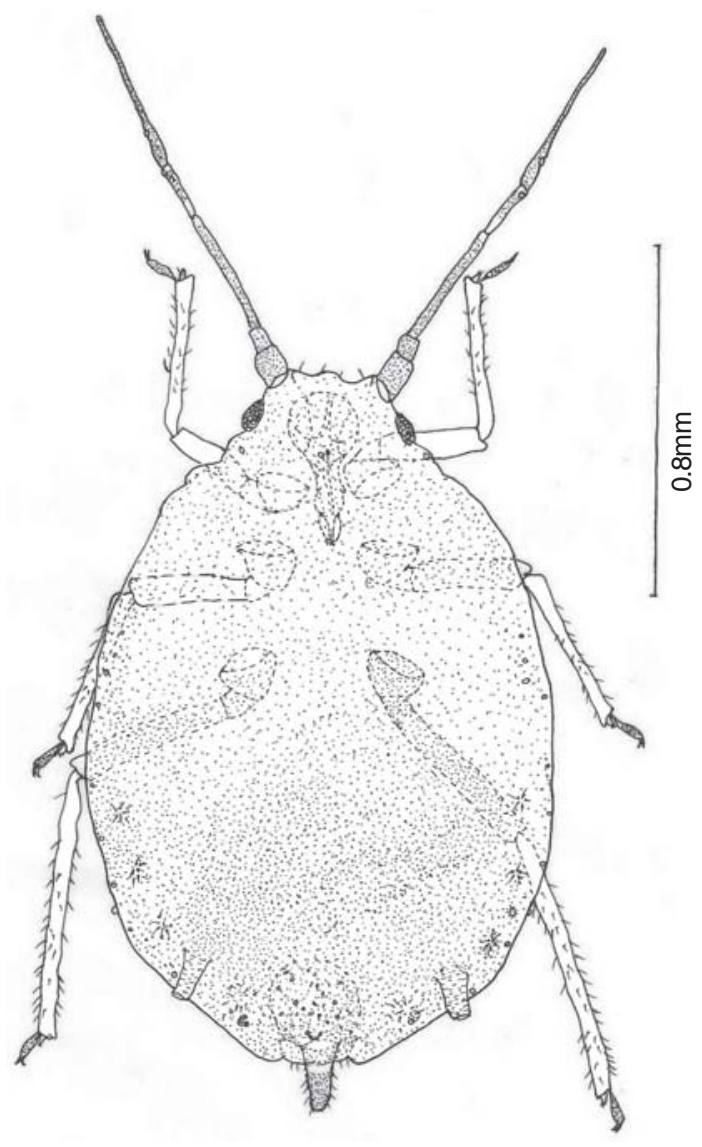

Figure 6. Rhopalosiphum rufiabdominalis (Sasaki) (Apterous) 


\section{Conclusion}

There are 36 genera and 58 species of aphids recorded from U.P. Most of them have been recorded from the hills, now in Uttarakhand State. More than 38 species of aphids are known from northeastern Uttar Pradesh (Singh et al. 1999; Ahmad \& Singh 2007). Data is deficient in plains and hence this study. Five species belonging to two genera of the tribe Aphidini from I.A.R.I. campus New Delhi, Aligarh and abutting remote areas are recorded. This is the first report from Aligarh region.

\section{References}

Ahmad, M.E. \& R. Singh (2007). Tritrophic relation of aphids (Homoptera: Aphididae) infesting vegetable plants in northeast Uttar Pradesh. Journal of Aphidology 21: 89-95.

Blackman, R.L. \& V.F. Eastop (2000). Aphids on the World's Crops: An Identification and Information Guide. 2nd edition. John Wiley \& Sons, New York, 466pp.
Eastop, V.F. \& D.H.R. Lambers (1976). Survey of the World's Aphids. The Hague: Junk, 573pp.

Ghosh, A.K. (1969). On a collection of Aphids (Homoptera: Aphididae) from Uttar Pradesh, India. Science and Culture 35: 493.

Ghosh, L.K. \& R.C. Basu (1994). Insecta: Hemiptera: Aphididae. State Fauna Series 3. Fauna of West Bengal, part 5: 125-318.

Kulkarni, P.P. (2006). Insecta: Aphidoidea: Aphididae, Zool. Surv. India. Fauna of Sanjay Gandhi National Park (Invertebrates) Conservation Area Series 26: 51-63.

Rajendran, T.P. (2002). Ecology and diversity of aphids (Homoptera: Aphididae) in the Indian region - a thesis for future investigation. Journal of Aphidology 16: 203-208.

Raychaudhari (1980). Aphids of Northeast India and Bhutan. The Zoological Society Calcutta, $521 \mathrm{pp}$.

Singh, R., B.S. Upadhya, D. Singh \& H.S. Choudhary (1999). Aphids (Homoptera: Aphididae) and their parasitoids in northeastern Uttar Pradesh. Journal of Aphidology 13: 49-62. 